\title{
Data-Driven High Collision Location Identification and Corrective Countermeasures on Roads in Kenya
}

\author{
S. N. Osano* , K.O. Amollo** , R.O. Ouko ${ }^{* *}$ \\ * Department of Civil and Construction Engineering, University of Nairobi \\ *** Transport Section, SMEC International Pty. Limited \\ DOI: 10.29322/IJSRP.10.10.2020.p10607 \\ http://dx.doi.org/10.29322/IJSRP.10.10.2020.p10607
}

\begin{abstract}
Road traffic crashes are recorded for various reasons such as establishing the damage, to estimate the economic cost of road crashes and to use this information to adequately plan and provide safer road transport infrastructure. In Kenya, the Traffic Police Department record crash information since they are always the first to attend to accident scenes. The data recorded by Traffic Police may often be counterchecked through the Ministry of Health (M.o.H) at the hospital level for post-crash and trauma care as well as organizations offering paramedicine services. Varying scales of injury may only be determined at the hospital during road crash injury management and prevention hence the need to establish an integrated data management system.
\end{abstract}

Road safety data collection processes have a great impact on the choice of an effective road safety intervention/measure since it majorly relies on the judgment and decisions of the traffic police and road safety officers. 'Safe System Approach' advocates for a sustainable safety solution in road transport through total involvement of persons and activities during planning, design, construction, operation and management of the roadway. This system identifies persistent errors in the road transport system that have been associated with causes of road traffic crashes.

This research paper identifies the existing gaps in better road safety management which would include inaccuracy in data collection and analysis leading to poor road safety treatments/countermeasures. It also demonstrates that through identification of key safety performance indicators, the lead agency in road safety in Kenya can prioritize the use of funding for road safety in order to achieve better results.

Many Low and Middle-Income countries have deficiency in road safety data collection and analysis and this has a negative impact on better road safety management. Ordinarily, Kenya Traffic Police have the mandate to record road accident data but this has also been a hindrance in the level of accuracy of the data. Most of the data recorded has not been analysed properly to reveal better strategies to improve road safety. This paper will demonstrate how a data-driven high collision identification system can largely improve blackspot management through developing and implementing possible countermeasures to the road safety problems as a way of minimising crash risk.

Index Terms- Crash Data Analysis, Engineering Interventions, Road Safety.

\section{INTRODUCTION}

Tn 2018, injuries due to traffic accidents were rated the eighth primary cause of mortality among people of all ages [1]. Most road traffic deaths involve vulnerable road users including pedestrians and cyclists in developing countries. [2]. In developing countries alone, injuries due to crashes contribute to about $85 \%$ of road traffic deaths globally compared to about $7 \%$ in high income countries [1]. The decade of action (2011-2020) on road safety failed to achieve the target of reducing road traffic deaths by $50 \%$ hence a majority of governments gathered in Stockholm in February 2020 to discuss possible interventions for the vision 2030 for road safety by adopting the Stockholm Declaration on Road Safety [3]. In a separate publication by members of the academic expert group, it has been suggested that better road safety management will incorporate collaboration between Governments, Non-governmental Organizations, Academia, Manufacturers, Road Agencies and Industry to achieve positive results on prevention of road traffic deaths in addition to sustainable practices and reporting as one of the practices countries should adopt. [4].

\section{METHODOLOGY}

The data collection was coordinated through the Kenya Police Headquarters in Ruaraka in Nairobi and involved obtaining data from 121 police bases all over the country. This was achieved in close liaison with the National Traffic Department. The data received was in hard copy for complete years of 2011 to 2016. The hard copy data was entered in Excel tables and analysed on the national, regional, corridor and sectional detail. Finer analysis at specific locational level was also carried out.

To enable complete analysis to establish trends, rigorous the data cleaning and modifications was conducted. The information in the forms as received from the police records was very general and not useful for the purposes of transportation planning and designing of road safety countermeasures hence the need for an extensive data cleaning.

The traffic volumes (ADT) data represented 2014 data from Kenya Roads Board. This data was supplemented with historical data from past projects undertaken on Kenya National Highways Authority (KeNHA) roadways where information was available. 
In addition, some information was obtained from National Transport and Safety Authority (NTSA) from their public portal.

\section{RESULTS AND ANALYSIS}

The data was processed and analysed to provide trends in accident occurrence, severity as well as to identify areas of high collisions or Black Spots.

\section{A. Annual Trends}

Nationally, a total of 28,030 crashes were reported and recorded for complete years 2011 to 2016 . The crashes were characterised as fatal, serious or slight injury. The property damage crashes were not recorded. The trend shows a decreasing number of crashes over the years with the highest occurrence in 2011 at 5477 and the lowest in 2016 at 4036 occurrences, amounting to $1 \%$ to $14 \%$ year over year reduction as illustrated on Figure 1.

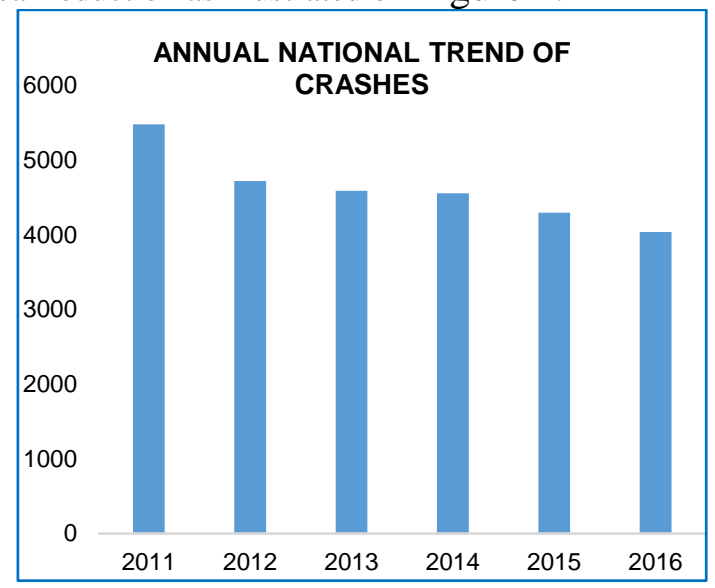

Figure 1: National Annual Trend of Crashes

Table 1 below gives a summary of some of the general statistics.

Table 1: National General Statistics

\begin{tabular}{|l|c|c|c|c|c|c|}
\hline $\begin{array}{l}\text { Total No of } \\
\text { crashes }\end{array}$ & 5477 & 4718 & 4587 & 4554 & 4296 & 4036 \\
\hline $\begin{array}{l}\text { No of Fatal } \\
\text { crashes }\end{array}$ & 2203 & 2040 & 2193 & 2182 & 2257 & 2017 \\
\hline $\begin{array}{l}\text { No of } \\
\text { Casualties }\end{array}$ & 5477 & 4718 & 4587 & 4554 & 4296 & 4036 \\
\hline $\begin{array}{l}\text { No of } \\
\text { Fatalities }\end{array}$ & 2576 & 2378 & 2567 & 2516 & 2631 & 2418 \\
\hline $\begin{array}{l}\text { Fatalities/ } \\
\text { 100000 } \\
\text { inhabitants }\end{array}$ & 5.840 & 5.408 & 5.813 & 5.784 & 5.983 & 5.347 \\
\hline $\begin{array}{l}\text { Fatalities/ } \\
\text { 10000 } \\
\text { vehicles }\end{array}$ & 13.626 & 11.398 & 10.9 & 9.869 & 9.184 & 8.207 \\
\hline
\end{tabular}

\section{B. Type of Crashes}

A review of the accident type shows that $29 \%$ of the crashes involved pedestrians, $2 \%$ pedal cycles, $22 \%$ involved motor cycles, while $47 \%$ involved other motor vehicles including heavy goods vehicles and cars either singularly or with each other as illustrated in Figure 2.

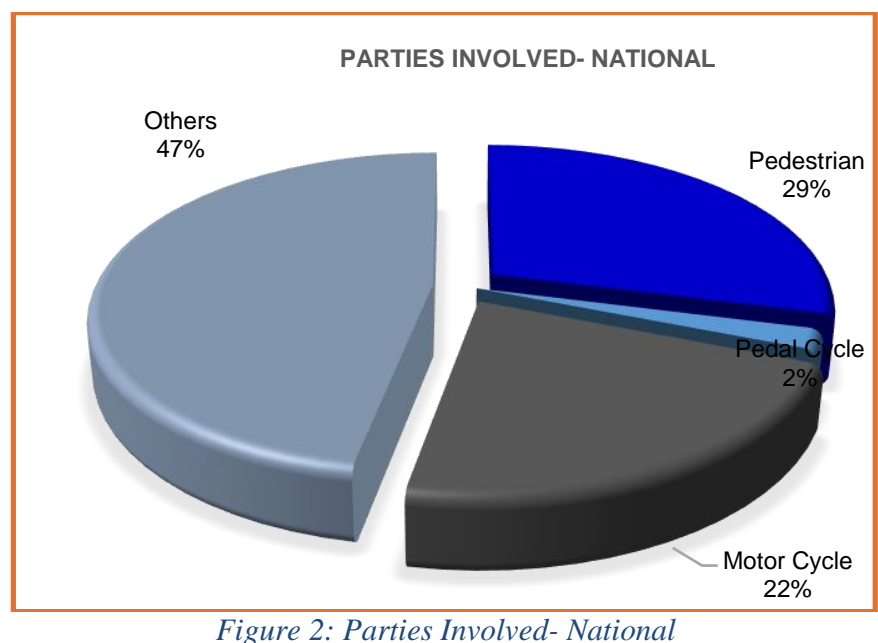

Nairobi region recorded the highest number of pedestrians involved crashes accounting for 54\% of the regional total with the lowest being Eastern region at $6 \%$. Western region recorded the highest pedal cycle and motor cycle involved crashes at $4 \%$ and $40 \%$ respectively. In the remaining regions, pedestrian involved crashes averaged between $20-25 \%$.

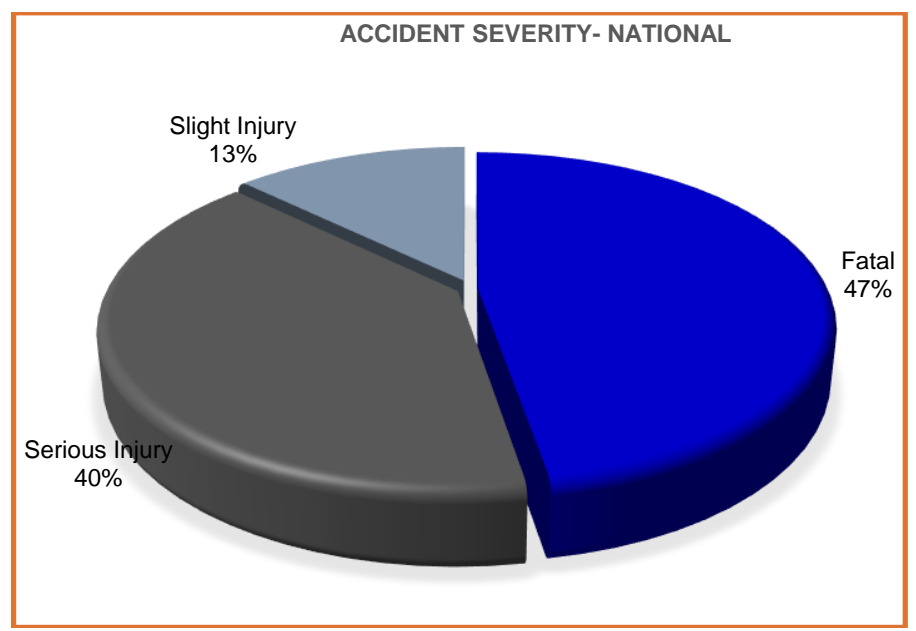

Figure 3: Accident Severity- National

Fatal crashes accounted for $47 \%$ of the total number of crashes, serious injuries $40 \%$ while slight injuries $13 \%$ as indicated on Figure 3. On the analysis of the likelihood of a fatal crash occurring, Nyanza region recorded the highest at 64\%, meaning in case of a crash, the likelihood of it resulting into death was 0.64. Nairobi had the lowest fatal crash probability at 0.34 ; attributable to the road network being mostly urban and therefore the vehicle 
operating speeds are controlled. Five out of the eight regions recorded probability of a fatal crash at more than 0.5 as illustrated on Figure 4.

\section{Time of Day Distribution}

The time of day distribution of the crashes was $64 \%$ to $36 \%$ as shown in Figure 5. The hourly distribution of the crashes exhibits two peaks; one in the mid-morning between nine am to one pm in the afternoon and the second peak in the evening from five to nine in the evening. The increase in the number of crashes is attributed to the high volume of traffic during both periods.

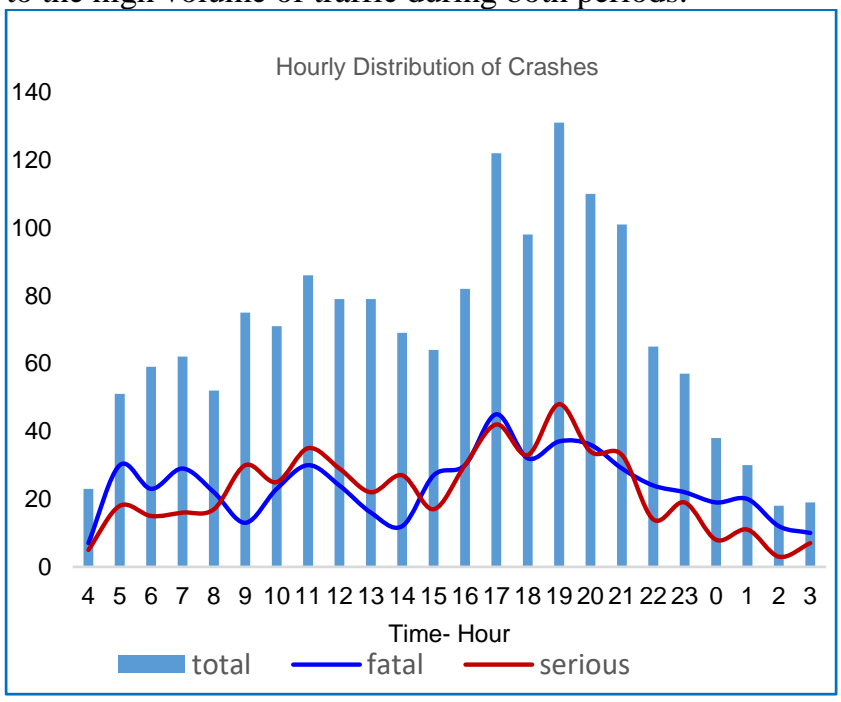

Figure 5: Hourly Distribution of Crashes

\section{Causes of Crashes}

The likely causes of any crash is recorded using over 120 cause codes that the investing police offices assigns based on their assessment of the collision site. The list of causes codes used by Traffic Police was retrieved from the police department. Figure 6 shows the most common accident causes recorded during the analysis period.

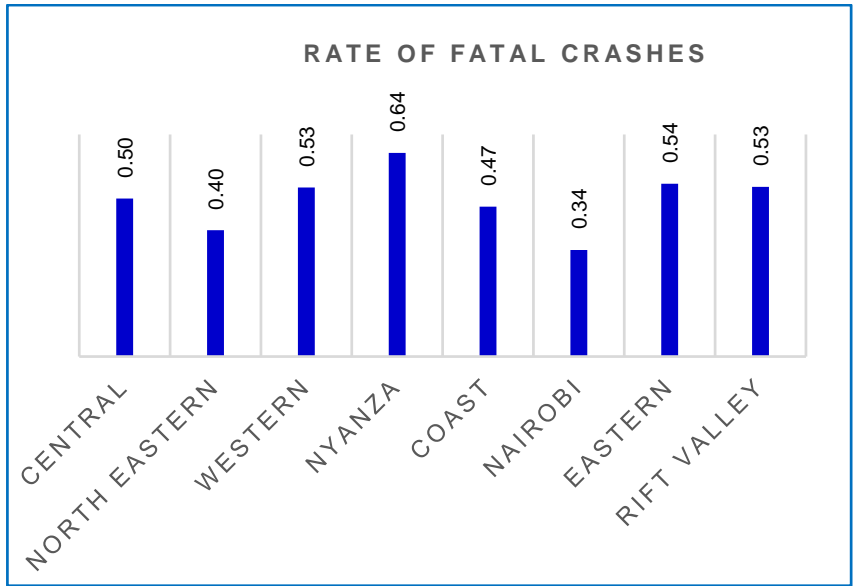

Figure 4: Likelihood of Occurrence of Fatal Crashes- National

\section{Highest Causes of Crashes- National}

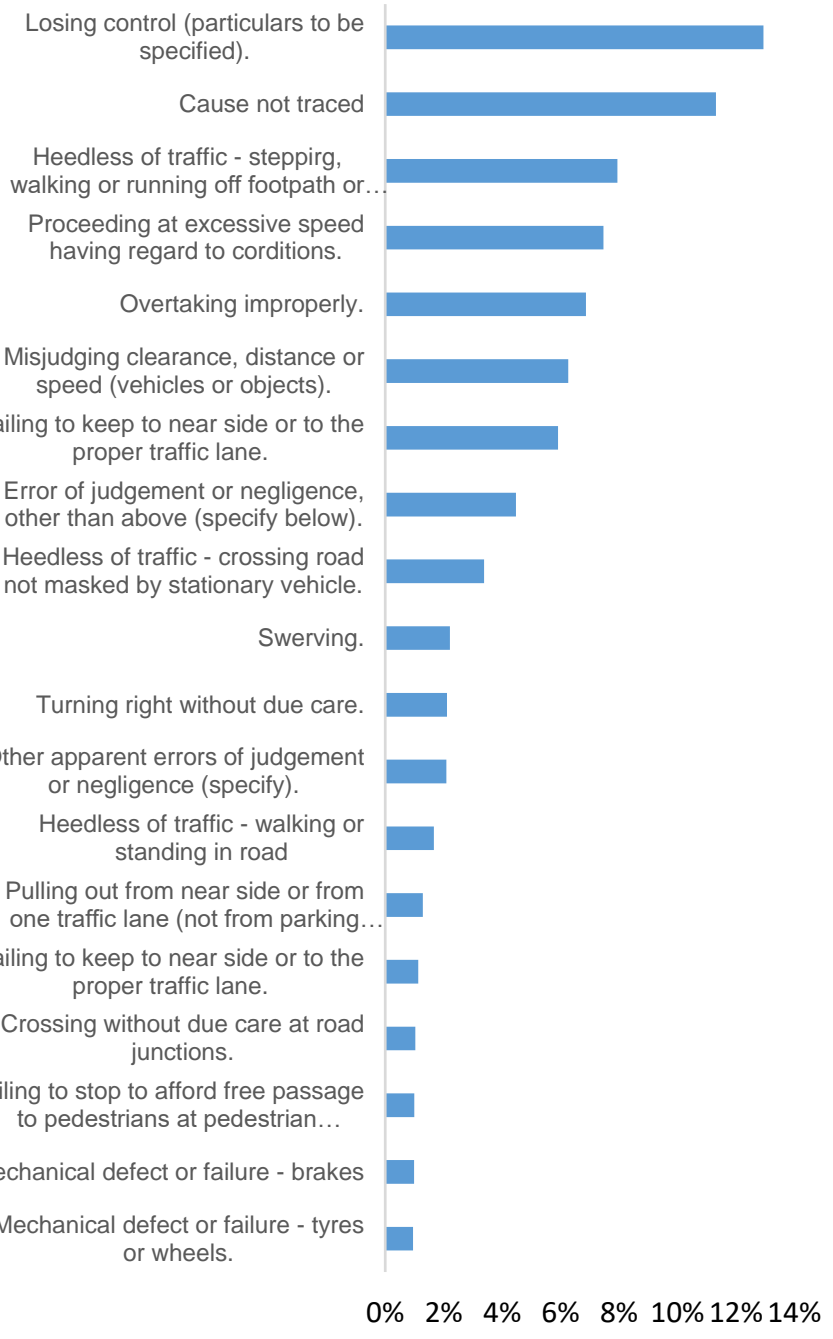

Figure 6: Causes of Crashes- National 
The trends point to the following facts:

- Losing control, proceeding at excessive speeds and overtaking improperly formed the three of the five highest causes of accidents nationally, pointing to high speeding as being a major detriment to road safety. This is compounded by the high pedestrian volumes that generally use the roadway corridors considering effects of high-speed differentials.

- Pedestrian issues contributed to $5822(20 \%)$ of the crashes. These included issues such as heedless of traffic while crossing, walking, standing or playing on the road as well as slipping and falling.

- 6495 crashes were due to speeding and loss of control making up $22 \%$ of the crashes. Related to this was poor manoeuvring such as cutting in, swerving, overtaking improperly and right turning which contributed $14.5 \%$ of the crashes.

- $\quad$ Errors in judgement and negligence such as misjudging clearance, distance or speed and failing to comply with traffic signals, crossing without due care at junctions and pedestrian crossings and reversing negligently caused $6727(23 \%)$ of the crashes.

- Only a paltry 130 crashes $(0.4 \%)$ were attributed to the condition of the road such as slippery road surface, poor road condition another road conditions.

- Of great concern is the percentage of crashes that are attributed to unknown causes which was the second highest code. This points to inability of the investigating officer's inability to assess the most probable cause and hence poor quality of the data collection process.

\section{E. Casualties}

Analysis of the number of casualties involved in the crashes depict a reducing trend from 2011 to 2016, generally following the overall accident trends as already noted. However, disaggregated data on the casualties (age, gender, road user type) was not available from the Traffic Police at the time of data collection. Figure 37 illustrates the national annual trend in the number of casualties from 2011 to 2016.

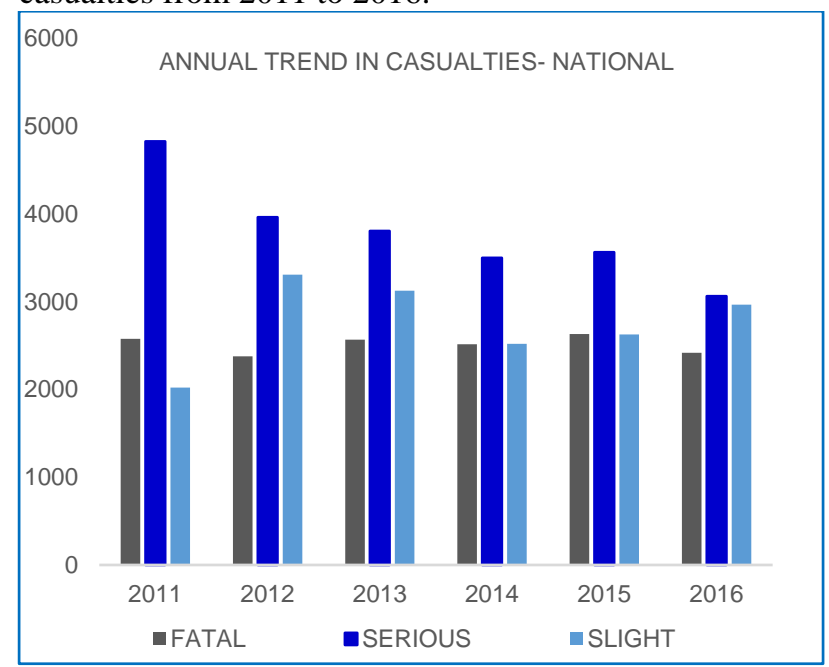

Figure 7: Annual Trend in Casualties- National
While the comparative analysis of the data obtained from the Traffic Police and the official records in the Statistical Abstract depict similar trends in reduction in number of casualties over the years, there is a variance in the number of casualties over the same period. The discrepancy in number of fatal crashes averages about 580 annually, with the highest discrepancies in numbers evident in the slight injury crashes. Table 2 below better illustrates this.

Table 2: Comparative Analysis of Number of Casualties- National

\begin{tabular}{|c|c|c|c|c|c|c|c|}
\hline & YEAR & 2011 & $\mathbf{2 0 1 2}$ & $\mathbf{2 0 1 3}$ & $\mathbf{2 0 1 4}$ & $\mathbf{2 0 1 5}$ & $\mathbf{2 0 1 6}$ \\
\hline \multirow{2}{*}{$\begin{array}{c}\text { Data from the } \\
\begin{array}{c}\text { Statistical } \\
\text { Abstract } \\
(2016)\end{array}\end{array}$} & FATAL & 3302 & 3141 & 3191 & 2907 & 3057 & 2965 \\
\cline { 2 - 8 } & SERIOUS & 8467 & 7434 & 6299 & 5140 & 4731 & 4661 \\
\cline { 2 - 8 } & SLIGHT & 7144 & 5037 & 4934 & 3971 & 4350 & 5533 \\
\hline $\begin{array}{c}\text { Primary Data } \\
\text { obtained } \\
\text { from the } \\
\text { Traffic Police } \\
\text { Headquarters }\end{array}$ & SERIOUS & 4825 & 3962 & 3805 & 3498 & 3562 & 3061 \\
\cline { 2 - 8 } & SLIGHT & 2022 & 3307 & 3124 & 2519 & 2627 & 2965 \\
\hline
\end{tabular}

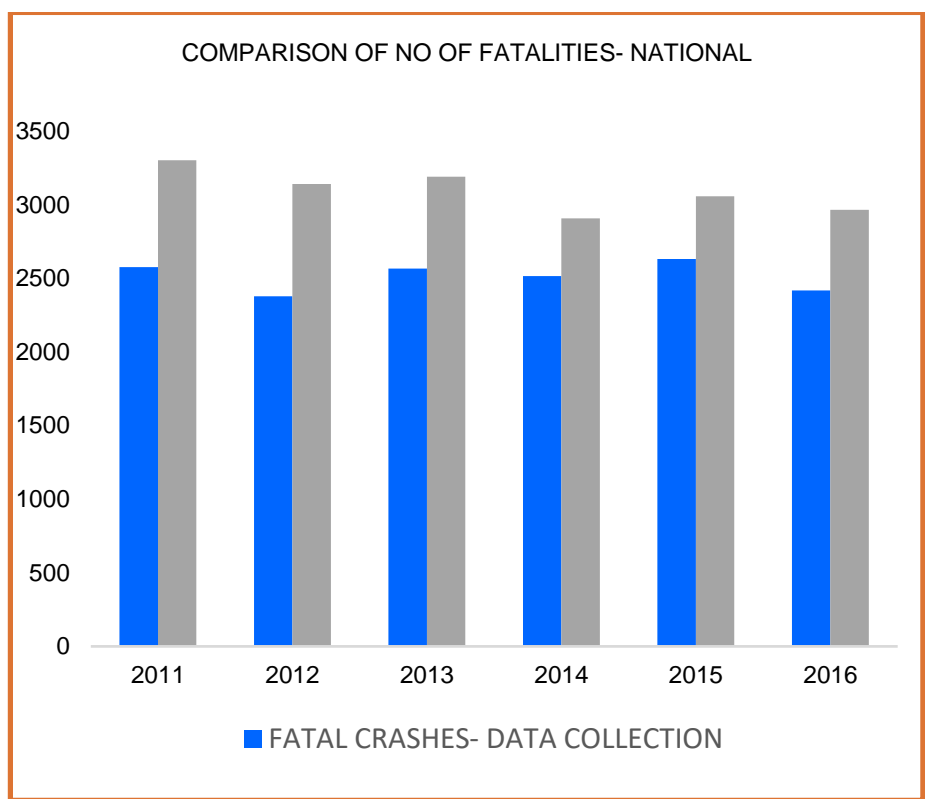

Figure 8: Comparative Analysis of the Number of Fatalities- National

Figure 8 above illustrates the comparison of the number of fatalities of the data from statistical abstract and the data collected form the Traffic police department. The two sets exhibit a similar trend of reduction of number of fatalities from 2011 to 2016. 2011 shows the highest number for both cases decreasing gradually over the years with slight peaks in 2013 and 2015. The discrepancy in numbers could be attributed to the misreporting of data from the local police stations during the exercise. 


\section{F. High Accident Locations}

Detailed analysis of high accident locations and Black Spots was established using the observed trends. The Figure 9 shows the top ten high accident locations nationally. Up to 120 crashes were recorded on those locations over the six-year period.

The top ten high accident locations are all along the major highways. The high volumes of traffic and the conflict of the road users contribute to the high rate of crashes. Further to this, all the top ten locations are along the Northern Corridor. While the crash rates remain high along the Northern Corridor, there have been previous numerous efforts geared towards enhancing the road safety.

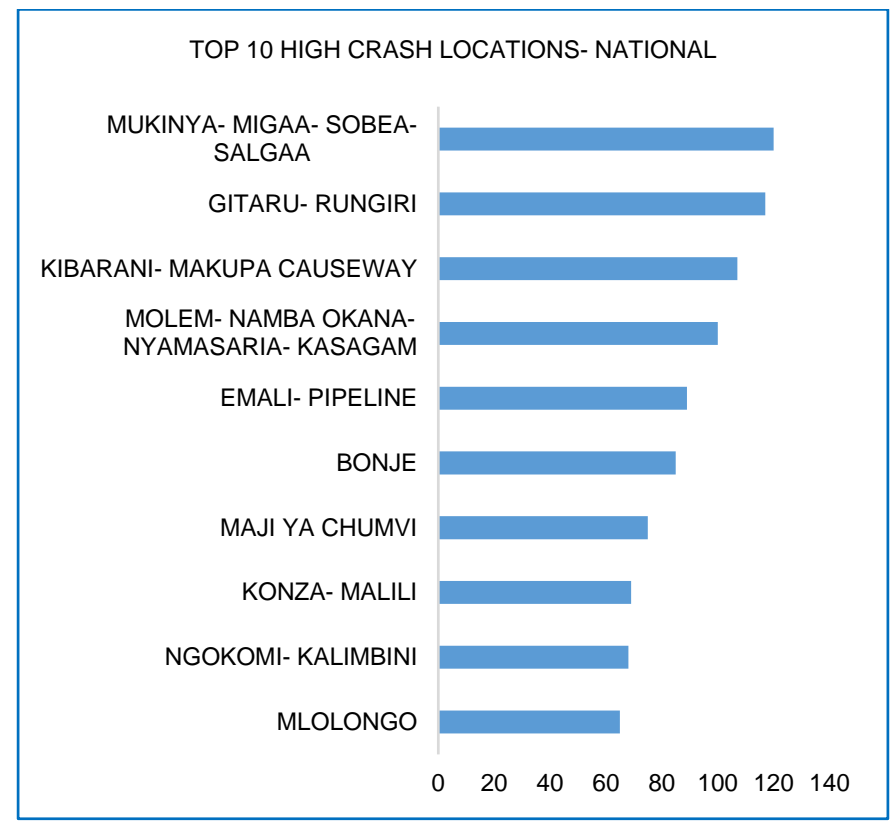

Figure 9: Top Ten High Crash Locations- National

\section{Black SPOT ENGINEERING COUNTERMEASURES}

Road safety challenges are often divided into two major groups including delineation safety problems at Black Spots and Geometrical Infrastructure deficiency induced blackspots or lengths as candidate spots and sections. Delineation safety problems include missing road markings, missing vertical directive, regulatory, warming and information signs as well as missing rumble strips, roadside guardrails and barriers protecting motor vehicles against run-off. On the other hand, geometrical infrastructure deficiency induced black spots or lengths as candidate spots and sections and the negative impacts such as elevation and cross-sectional slopes and curvatures on the roadway and pavement proper.

\section{A. Infrastructure induced Black Spots}

Infrastructure induced black spots occur due to inaccurate road design and construction processes. These black spots are often linked to inadequate design of the highway geometry to accommodate vehicular traffic travelling at particular speeds. However, there are a number of Engineering Countermeasures that can be established for the deficiencies that come due to insufficient engineering provisions. These deficiencies include poor asphalt pavement surface conditions, sharp horizontal curvature, blurred visibility and short distances, insufficient crosssectional geometry, reduced lane widths, insufficient shoulder widths, lack of crash barriers, steep embarkment and clear zones, absence of rumble strips, separators between pedestrians and cyclist from motorized vehicles, conflict points at cross road, intersections, interchanges and roadside link, missing delineation, road marking, road studs, absence of warning signs.

Some of the corrective engineering measures/remedial actions may be sorted in rectifying the shortfalls in the construction process. The measures are categorized into five major groups such as delineation hazard management, Traffic signs and road markings, traffic calming measures, black spot pavement damage rehabilitation and voluminous roadway body reconstruction at blackspot locations.

Delineation hazard management involves establishing roadside clear zones, free of obstruction by fixed objects such as electrical poles, trees, boulders and culvert parapets; roadside crash barriers, guardrails and bridge end protection. Others include roadside design elements such as shoulders, verges, embarkments and drains, reliance on sight distance and roadside encroachment by street markets. Traffic signs and road markings such as centreline, double centreline, edge-line, reflective studs, and intersection line markings. Traffic signs have a significant impact on driver awareness on the road and such signs including vertical traffic signs and chevron signs have a positive impact on road safety. Traffic calming measures include speed control measures such as rumble strips, gates and speed breaking humps for motorized traffic. For non-motorized traffic such as pedestrian and cyclists, other measures have proven to be more effective such as separation of vulnerable road users from motorized traffic by use of kerbs, sidewalks, cycleways, pedestrian safety fences and crossings, pedestrian refuge islands and bus bays.

Pavement rehabilitation at black spots have the possibility of improving road safety especially in areas where pavement failure involves rutting, bulging, potholes, fragmentation, fissurization and edge failure in wearing and binder asphalt courses. Pavement settlement at bridge approaches or insufficient compaction on road base layer can be hazardous to motorized traffic. Other roadway failure leading to blackspots include areas of potential rock falls from cut slopes, mud flow, landslides, subgrade washout by adjacent rivers and failure on high embarkments due to blockage of seepage water.

\section{B. Remedial Accompanying Measures}

Whereas corrective engineering measures alone cannot resolve the safety gaps or problems at most dangerous spots and sections, significantly more attention needs also to be given to aspects, which are within the domain of responsibility of NTSA, e.g.:

i. Increased traffic police presence by patrolling most dangerous hilly and winding road sections, thereby focussing on over-speeding and careless overtaking (Act No. 33 of 2012, Clause 4. (1) (d) "ensure the provision of safe, reliable and efficient road transport services" 
ii. Targeting ignorant pedestrians and bicyclists in educational campaigns on dangers of high-speed roads (Act No. 33 of 2012, Clause 4. (2) (f) "facilitate the education of members of the public on road safety")

iii. Better driver education in driving schools with higher quality control standards (Act No. 33 of 2012, Clause 4. (2) (i) "establish systems and procedures for, and oversee the training, testing and licensing of drivers"

iv. Stricter theoretical and practical driver examination with participating judgement by traffic police (Act No. 33 of 2012, Clause 4. (2) (b) "conduct motor vehicle inspections and certification"

\section{CONCLUSION AND RECOMMENDATION}

Road safety is a critical component of building a better society. It is therefore important to incorporate road safety audit strategies in the development of road infrastructure. The intention of the road safety audits is to evaluate the road system and identify gaps that would lead to crashes for timely mitigation for prevention of crash occurrence.

It is also important for road agencies and safety organisation to enhance crash data collection by development of automated procedures. The procedures should encompass the use of a checklist that immediately identifies the possible countermeasures that can be utilised to diagnose the identified gaps for immediate rectification.

\section{REFERENCES}

[1] World Health Organization, (2018). Global Status Report on Road Safety 2018: Geneva, Switzerland

[2] World Health Organization, (2013). Pedestrian Safety: A Road Safety Manual for Decision Makers and Practitioners: Geneva, Switzerland.

[3] Stockholm Declaration on Road Safety, (2020). Third Global Ministerial Conference on Road Safety: Achieving Global Goals 2030: Stockholm, Sweden.

[4] Swedish Transport Administration, (2020). Saving Lives Beyond 2020: The Next Steps - Recommendations of the Academic Expert Group for the Third Global Ministerial Conference on Global Road Safety 2020.

[5] Wegman, F., Berg, H., Cameron, I., Thompson, C., Siegnst, S., Weijmers, W., (2015). Evidence-Based and Data Driven Road Safety Management. Journal of International Association of Traffic and Safety Sciences, (IATSS).
[6] Esperato, A., Bishai, D., Hyder, A. A., (2012). Projecting the Health and Economic Impact of Road Safety Initiatives. A case study of a multi-country project. Journal of Traffic Injury and Prevention

[7] Wegman, F. (2017). The Future of Road Safety: A worldwide perspective Journal of International Association of Traffic and Safety Sciences (IATSS)

[8] Wegman, F., Traffic Safety in: Van Wee, B., Annema, J. A, Banister, D., (Eds), The Transport System and Transport Policy. An Introduction, Edward Elgar, Cheltenham 2013, pp. 254-280

[9] OECD/ITF, Road Safety Annual Report, 2015) IRTAD Paris 2015

[10] African Development Bank (2013). Road Safety Manual for African Countries; Existing Roads: Reactive Approaches

\section{AUTHORS}

\section{First Author:}

Author name: Dr. Simpson Nyambane Osano

Qualifications: Senior Lecturer

Associated institute: University of Nairobi

Email address: sosano@uonbi.ac.ke

\section{Second Author:}

Author name: Kenneth Otieno Amollo

Qualifications: Civil Engineer

Associated institute: SMEC International Pty. Limited

Email address: kennethamollo27@gmail.com

\section{Third Author:}

Author name: Robert Ouko Oyoo

Qualifications: Civil Engineer

Associated institute: Kenya Institute of Highways and Building

Technology

Email address: robertsoyoo92@gmail.com

\section{Correspondence Author:}

Author name: Kenneth Amollo

Email address: kennethamollo27@gmail.com

Alternate email address: Kenneth.Amollo@smec.com

Contact number: +254714 198805 